\title{
TÁCTICAS TÉCNICAS LAPAROSCÓPICAS
}

\author{
José G abriel Valdivia Uría y Carlos Hernández Fernández² \\ ${ }^{1}$ Servicio de Urología. Hospital Clínico Universitario Lozano Blesa. Zaragoza \\ ${ }^{2}$ Servicio de Urología. Hospital G regorio M arañon. Madrid. España.
}

\section{ÍN DICE/ RESUMEN}

1. Tácticas en creación de neumoperitoneo.

$$
\text { J. G. Valdivia Uría. }
$$

2. Tácticas en colocación de trocares.

$$
\text { J. G. Valdivia Uría. }
$$

3. Abordaje retroperitoneal y creación de espacio en retroperitoneo.

$$
\text { J. G. Valdivia Uría y C. Hernández Fernández. }
$$

4. Tácticas en laparoscopia mano-asistida. J. G. Valdivia Uría y C. Hernández Fernández.

Palabras clave: Tecnica laparoscópica. C reación neumoperitoneo. Colocación trocares. Abordaje retroperitoneal. C reación de espacio en retroperitoneo. Laparoscopia mano-asistida.
José G abriel Valdivia Uría Servicio de Urología Hospital C línico Universitario Lozano Blesa Avda. San Juán Bosco, 15 50009 Zaragoza. (España)

\section{CREACIÓN DE NEUMOPERITONEO}

J. G. Valdivia Uría.

Clásicamente se crea el neumoperitoneo mediante una aguja de Veress. No obstante, las descripciones de esta técnica no suelen hacer referencia a la creación del neumoperitoneo con el paciente en decúbito lateral, situación muy frecuente en urología.

Cuando el paciente está en decúbito supino, se prefiere siempre como punto de entrada el contorno superior de la cicatriz umbilical, debido a que en esta zona el peritoneo está firmemente adherido a la pared abdominal y por consiguiente existe menos riesgo de crear un enfisema preperitoneal. La aguja debe cogerse como si fuera un dardo y al tiempo que se estabiliza la pared abdominal (pinzándola con los dedos o unos Backhaus) se profundiza con ella verticalmente hasta percibir que se vencen dos resistencias (la primera corresponde a la fascia transversalis y la segunda al peritoneo). Las agujas automáticas (desechables) además de poseer un indicador óptico, producen un "clic" en el momento en el que se ha atravesado el peritoneo y el fiador romo pasa a proteger la punta de la aguja.

Existen diversas maneras de comprobar que la aguja está bien situada: fácil introducción de líquido (en realidad éste es casi aspirado por una leve presión negativa), no retorno del mismo mediante aspiración con jeringuilla, y sobre todo una baja presión intraabdominal al inicio de la 
insuflación (siempre por debajo de $10 \mathrm{~mm}$ de $\mathrm{Hg}$ ). El insuflador debe programarse para que produzca inicialmente un flujo de 2 litros por minuto (por la aguja no pasa más flujo) y que no se sobrepase una presión intraabdominal de $15 \mathrm{~mm}$ de $\mathrm{Hg}$. Una vez colocados los trócares, el flujo de entrada debe situarse a 15 o 20 litros por minuto y reducirse la presión intraabdominal a sólo $10 \mathrm{~mm}$ de $\mathrm{Hg}$.

Sin embargo, cuando el paciente se encuentra en decúbito lateral, con pillet lumbar, la colocación de la aguja de Veress debe hacerse a nivel pararrectal, a nivel del ombligo o algo más abajo en el lado derecho. Existe más riesgo de despegar el peritoneo y crear un enfisema preperitoneal, así como de poder lesionar alguna víscera.

Muy importante: al comprobar la presión intraabdominal, al inicio de la insuflación, podemos encontrarnos con presiones más elevadas que en decúbito supino, debido a la compresión del pillet y el arqueamiento del abdomen.

\section{COLOCACIÓN DE LOS TRÓCARES}

\section{J. G. Valdivia Uría.}

Uno de los momentos más críticos de toda laparoscopia cerrada es el de la colocación del primer trócar. Este riesgo se halla incrementado siempre que exista el antecedente de una cirugía abdominal previa (posibles adherencias) o cuando se trata de un niño de corta edad (menor distancia de la pared abdominal al plano posterior).

Por ello, y a pesar de que hoy en día se dispone de trócares ciegos de avanzado diseño atraumático, provistos de sistemas de seguridad capaces de anular el efecto cortante 0 punzante de su punta en cuando se ha vencido la resistencia del peritoneo, nosotros preferimos realizar siempre el abordaje inicial bajo control visual, mediante un trócar óptico activo (Visiport ${ }^{\mathrm{TM}}$ ), tanto si hemos realizado o no, una insuflación previa con $\mathrm{CO}^{2}$ a través de una aguja de Veress.

Nuestra actual forma de proceder es la siguiente: Suponiendo que realizamos este abordaje con el paciente en decúbito lateral, realizamos un ojal cutáneo a nivel pararrectal y atravesamos el tejido subcutáneo y los distintos planos musculares con el trócar óptico, incidiendo las fascias y separando de manera roma los haces musculares, hasta alcanzar la fascia transversalis. Esta se distingue porque hace cuerpo con el peritoneo y deja casi transparentar el libre desplazamiento de las asas intestinales con los movimientos respiratorios. En ese momento, retiramos el elemento de trabajo del trócar (sujetando in-situ su camisa) y perforamos, a través de ella, con un suave golpe seco de las pinzas laparoscópicas de disección estas finas láminas. A brimos entonces el paso al $\mathrm{CO}^{2}$, (con un flujo de 15 litros por minuto) y comprobamos que rápidamente se distiende el abdomen. Reintroducido el elemento de corte del trocar óptico, completamos la apertura del peritoneo bajo control visual).

Muy importante: Hasta que no se adquiera una buena experiencia, aconsejamos que la colocación del trócar óptico se realice previa insuflación del abdomen con $\mathrm{CO}^{2}$ a través de una aguja de Veress.

M uy importante: en pacientes con antecedentes de laparotomías previas complicadas, o en niños de corta edad, debe preferirse siempre una laparoscopia abierta, es decir, introduciendo un trócar romo de Hasson a través de una microlaparotomía. Esta microlaparotomía puede hacerse a nivel del contorno superior del ombligo, o en un lugar alejado de cicatrices previas, siempre y cuando éste resulte favorable para el tipo de intervención a realizar.

\section{ABORDAJE RETROPERITONEAL Y CREA- CIÓN DE ESPACIO EN REIROPERITONEO}

J. G. Valdivia Uría.

En retroperitoneoscopia, el uso del trócar óptico hace innecesarios el balón de Gaur y el trócar de Hasson, evitando asimismo el riesgo de enfisema parietal.

Con el paciente en posición de decúbito lateral, el trócar óptico se introduce por un ojal cutáneo realizado en el flanco, en la zona media de una hipotética línea de lumbotomía subcostal. Tras atravesar los distintos planos se alcanza la fascia transversalis que se distingue por su intenso color blanco y trama paralela de sus fibras. Un último toque de cuchilla abre esta fascia y el extremo romo del trócar entra y desplaza 
con facilidad la grasa retroperitoneal, descubriendo el músculo cuadrado lumbar y el psoas. Retirado el sistema de trabajo (sujetando in-situ la camisa del trócar) se pasa la óptica y se abre paso al $\mathrm{CO}^{2}$ a un flujo de 15 litros por minuto y a una presión de $10 \mathrm{~mm}$ de $\mathrm{Hg}$.

Muy importante: con suaves y cortos movimientos de impulsión y lateralización de la óptica, apoyándola siempre en áreas de tejido laxo se obtiene rápidamente el espacio de trabajo requerido.

Si el abordaje queremos hacerlo al espacio preperitoneal, con el paciente en decúbito supino, introducimos el trócar óptico a través de un ojal cutáneo infraumbilical. Tras unos pocos disparos de cuchilla a parecen a la vista las fibras musculares de uno de los músculos rectos; éstas son separadas de manera roma por la cúpula transparente del trócar, quedando al descubierto la fascia transversalis que recubre al peritoneo. Dado que esta fascia transversalis desaparece unos centímetros más abajo, en dirección al pubis (arco de Douglas), debe cambiarse la dirección del trócar y sin efectuar ningún disparo más de cuchilla hacerlo progresar por detrás del plano muscular hasta sentir el contacto con la sínfisis púbica. Esta aparece a la vista como una estructura lisa, de color blanco azulado. En este momento se sustituye el sistema de trabajo del trócar por la óptica (sujetando in-situ su camisa) y tras dar paso al $\mathrm{CO}^{2}$, se crea el espacio de trabajo a nivel retropúbico mediante suaves y cortos movimientos de impulsión y lateralización de la óptica, apoyándola siempre en áreas de tejido laxo, eludiendo las zonas más vascularizadas.

M uy importante: algunas pacientes obesas, 0 que en su día lo fueron, pueden presentar una diástasis de los músculos rectos. En estos casos, es preferible lateralizar un poco la dirección del trocar óptico para ir al encuentro de alguno de los músculos rectos, y no caer directamente en la cavidad peritoneal.

\section{CREACIÓN DEL ESPACIO RETROPERITONEAL}

\section{Hernández Fernández}

El paciente es colocado en posición de lumbotomía. El cirujano se coloca en la espalda del paciente al igual que el ayudante. Se realiza una pequeña incisión de 1 centímetro aproximadamente por debajo de la punta de la 12 a costilla. Con disec- ción roma se alcanza la fosa pararrenal posterior y con el dedo se crea un espacio antes de insertar el primer trócar, éste ha de ser un trocar de Hasson que ocluya perfectamente el orificio creado.

A natómicamente el retroperitoneo es un espacio virtual y por lo tanto hay que generar una cavidad que nos permita la colocación del resto de los trócares y trabajar con ellos.

Podemos servirnos de un balón de dilatación de los que se comercializan por distintas compañías y que permiten introducir el laparoscopio por dentro de los mismos. De esta forma podemos visualizar, en tiempo real, la creación de dicho espacio y confirmar la correcta posición del mismo. Incluso, en ocasiones, se identifican algunas estructuras como el uréter o la vena cava.

Esta maniobra puede hacerse también de forma artesanal, introduciendo un dedo de guante atado en la punta de una sonda de nelaton. Por ella, y ayudados de una jeringa urológica de cono ancho, dilatamos el dedo de guante con suero salino pudiendo llegar a distender la cavidad con 1.000 cc, vaciandolo a un batea posteriormente.

En la actualidad no somos partidarios de crear éste espacio con ningún tipo de balón dilatador ya que se laminan los tejidos y dificulta, en parte, la disección e identificación de los mismos. En la actualidad después de colocado el primer trócar es el $\mathrm{CO}^{2}$ el que inicia la disección, e incluso nos servimos del propio laparoscopio para ir generando espacio de trabajo.

El segundo trócar se introduce paralelo a la 12 a a costilla, por debajo de ella y en el borde lateral del músculo sacroespinal. Siguiendo esa línea y en dirección anterior a nivel de la linea axilar posterior se coloca el tercer acceso.

Es el propio gas el que distiende el tejido areolar retroperitoneal y ya con pinza y tijera iniciamos la disección que nos permite identificar el músculo psoas y medial a él podemos disecar el uréter en su tercio proximal. Siguiendolo en dirección craneal alcanzamos el riñón en su polo inferior y al levantarlo se visualiza el hilio con la arteria en primer lugar y la vena por detrás, como corresponde al abordaje retroperitoneal. 
Al tener desde un principio al paciente en decúbito lateral y sin apertura del peritoneo, las asas intestinales quedan rechazadas por la presión del $\mathrm{CO}_{2}$.

Es importante destacar que, al ser el abordaje posterior, una vez alcanzado el hilio del riñón, el primer vaso en aparecer es la arteria renal, que puede ser clipada y seccionada, abordando posteriormente la vena.

\section{LAPAROSCOPIA MANO-ASISTIDA}

\section{J. G. Valdivia Uría.}

La laparoscopia manoasistida debería emplearse siempre que se tenga previsto realizar una nefrectomía o nefroureterectomía ampliadas, pues al final de estas técnicas es necesario extraer embolsada la pieza entera (con toda la grasa de Gerota), lo cual obliga incluso a ampliar la incisión inicial de $6 \mathrm{~cm}$ que solemos hacer para introducir nuestra mano izquierda en el abdomen (sin ningún sistema de oclusión complementario, tipo Handport ${ }^{\mathrm{TM}}$, Lapdisc ${ }^{\mathrm{TM}}$, etc.). M uy importante: aconsejamos realizar esta incisión de $6 \mathrm{~cm}$ en la línea media, contorneando la cicatriz umbilical, hacia el xifoides si se trata del riñón izquierdo, o hacia el pubis si se trata del derecho.

\section{CREACIÓN DE ESPACIO EN LAPAROSCOPIA MANO-ASISTIDA}

C. Hernández Fernández.

El abordaje con asistencia manual se contempla como un paso intermedio entre la cirugía abierta convencional y la puramente laparoscópica. Con esta técnica pueden superarse, sobre todo en la curva de aprendizaje, algunas de las limitaciones y frenos que para el urólogo tiene el iniciarse en la técnica endocavitaria como son la pérdida de la sensación táctil, el control inmediato de un inesperado sangrado y un tiempo quirúrgico de entrada más corto.

El paciente se coloca en posición lateral con una inclinación de entre $15-30^{\circ}$, la incisión manual puede hacerse en la linea media por encima y debajo del ombligo o en la fosa ilíaca. La longitud de la incisión coincide en centímetros con el tamaño de guante que utiliza el cirujano.

En esta herida se introduce el dispositivo de acceso manual, que permite introducir la mano no dominante del cirujano sin que se pierda $\mathrm{CO}_{2}$.

En muchas ocasiones si la apertura se ajusta al diámetro de la mano puede obviarse la utilización de los dispositivos tipo "omniport" ya que con la distensión del gas, la pared abdominal se adapta a la muñeca del cirujano y la pérdida de gas es pequeña. De esta forma simplificamos el procedimiento y lo hacemos menos costoso.

El resto de accesos se colocan, dependiendo de donde se haya realizado la primera incisión aunque la mayoría de autores los colocan en la linea axilar anterior, de tal manera que la mano interfiera la visión del laparoscopio lo menos posible. Mientras la mano del cirujano tensa los tejidos, con la contraria se maneja un instrumento de coagulación y corte tipo "ligasure" o bisturí armónico lo que facilita la disección y acorta mucho los tiempos quirúrgicos. 